Research Paper

\title{
Comprehensive study of prognostic risk factors of patients underwent pneumonectomy
}

\author{
Chang Gu1 , Rui Wang ${ }^{1}$, Xufeng Pan ${ }^{1}$, Qingyuan Huang11, Jizhuang Luo ${ }^{1}$, Jiajie Zheng1, Yiyang Wang1, \\ Jianxin Shi ${ }^{1 凶}$, Haiquan Chen ${ }^{1,2 \bowtie}$ \\ 1. Department of Thoracic Surgery, Shanghai Chest Hospital, Shanghai Jiao Tong University, Shanghai, China \\ 2. Department of Thoracic Surgery, Fudan University Shanghai Cancer Center, Shanghai, China \\ Chang Gu, Rui Wang and Xufeng Pan contributed equally to this work. \\ $\square$ Corresponding author: Haiquan Chen, Department of Thoracic Surgery, Shanghai Chest Hospital, Shanghai Jiaotong University, 241 West Huaihai Road, \\ Shanghai 200030, China. E-mail: chenhq_sch@sina.com and Jianxin Shi, Department of Thoracic Surgery, Shanghai Chest Hospital, Shanghai Jiaotong \\ University, 241 West Huaihai Road, Shanghai 200030, China. E-mail: shijianxin_sch@126.com \\ (c) Ivyspring International Publisher. This is an open access article distributed under the terms of the Creative Commons Attribution (CC BY-NC) license \\ (https:// creativecommons.org/licenses/by-nc/4.0/). See http://ivyspring.com/terms for full terms and conditions.
}

Received: 2017.02.02; Accepted: 2017.04.01; Published: 2017.07.05

\begin{abstract}
Introduction: To investigate postoperative complications and the prognostic risk factors of patients underwent pneumonectomy.

Methods: Four hundred and six patients underwent pneumonectomy were subjected to the study. All the clinicopathologic data including age, gender, smoking history, surgical treatment, postoperative complications, tumor staging and the follow-up information were investigated.

Results: The 30-day and 90-day mortality rates were $3.2 \%$ and $6.2 \%$, respectively. Postoperative complications developed in 149 patients (36.7\%), mainly included arrhythmia, transfusion, pulmonary infection, bronchopleural fistula and acute respiratory distress syndrome. During the follow-up, 189 patients experienced a relapse, consisting of 51 patients with local recurrence and 138 with distant recurrence. The median survival time was 24.4 months and the overall 1-year, 3 -year and 5 -year survival rates were $82.7 \%, 50.9 \%$ and $32.5 \%$, respectively. Moreover, the overall 1-year, 3-year, 5-year survival rates for patients with non-small cell lung cancer (NSCLC) were $84.1 \%, 52.1 \%$ and $32.5 \%$, respectively and patients with small cell lung cancer (SCLC) were $56.1 \%$, $38.5 \%$ and $28.8 \%$, respectively. Among NSCLCs, adenocarcinomas had a worse prognosis than squamous carcinomas. Compared to right pneumonectomy, patients with left pneumonectomy had a better prognosis. Multivariable analysis revealed ICU stay, disease stage, nodal stage and adjuvant chemotherapy were all significant predictors of overall survival (OS).

Conclusions: Pneumonectomy is still a valuable and effective treatment option for patients with advanced lung cancer. Surgeons should be more cautious when patients had higher disease stage, adenocarcinoma and right-side lung cancer. Neoadjuvant chemotherapy did not affect the prognosis. Pneumonectomy could also achieve acceptable survival outcomes in well-selected SCLC patients.
\end{abstract}

Key words: Pneumonectomy; Prognosis; Small cell lung cancer; Non-small cell lung cancer

\section{Introduction}

Lung cancer maintains the leading cause of cancer-related death in the world and surgical resection could offer a potential cure for patients with resectable malignant lung neoplasms [1, 2]. Although sleeve lobectomy, with less reduction of respiratory function and a lower mortality rate, would not compromise oncological results in well-selected patients with central lung cancer, pneumonectomy is still necessary when complete resection could not be achieved by other surgical procedures $[3,4]$. 
Table 1: Clinicopathologic data of patients underwent pneumonectomy.

\begin{tabular}{|c|c|c|}
\hline Variable & $\mathbf{N}$ & $\%$ \\
\hline \multicolumn{3}{|l|}{ Age, yrs } \\
\hline$<60$ & 224 & 55.2 \\
\hline$\geq 60$ & 182 & 44.8 \\
\hline \multicolumn{3}{|l|}{ Sex } \\
\hline Male & 357 & 87.9 \\
\hline Female & 49 & 12.1 \\
\hline \multicolumn{3}{|l|}{ Smoking history } \\
\hline Never & 65 & 16.0 \\
\hline Ever & 341 & 84.0 \\
\hline \multicolumn{3}{|c|}{ Side of pneumonectomy } \\
\hline Left & 298 & 73.4 \\
\hline Right & 108 & 26.6 \\
\hline \multicolumn{3}{|l|}{ Pathology } \\
\hline Adenocarcinoma & 89 & 21.9 \\
\hline Squamous carcinoma & 261 & 64.3 \\
\hline Small-cell lung cancer & 22 & 5.4 \\
\hline Others & 34 & 8.4 \\
\hline $\mathrm{T}$ size, $\mathrm{cm}$ & $4.99(1.0-17.0)$ & \\
\hline \multicolumn{3}{|l|}{ pT stage } \\
\hline 1 & 45 & 11.1 \\
\hline 2 & 195 & 48.0 \\
\hline 3 & 75 & 18.5 \\
\hline 4 & 91 & 22.4 \\
\hline \multicolumn{3}{|l|}{$\mathrm{pN}$ stage } \\
\hline 0 & 45 & 11.1 \\
\hline 1 & 148 & 36.4 \\
\hline 2 & 213 & 52.5 \\
\hline \multicolumn{3}{|l|}{ pM stage } \\
\hline 0 & 396 & 97.5 \\
\hline 1 & 10 & 2.5 \\
\hline \multicolumn{3}{|l|}{ pStage } \\
\hline Ia & 10 & 2.5 \\
\hline $\mathrm{Ib}$ & 18 & 4.4 \\
\hline IIa & 75 & 18.5 \\
\hline $\mathrm{IIb}$ & 24 & 5.9 \\
\hline IIIa & 213 & 52.5 \\
\hline $\mathrm{IIIb}$ & 56 & 13.7 \\
\hline IV & 10 & 2.5 \\
\hline
\end{tabular}

Pneumonectomy is considered as a high-risk procedure, which is reported with higher morbidity and mortality [5, 6]. In recent years, with the improvement of anesthesia, surgical technique and perioperative nursing, the operative mortality relevant to pneumonectomy has significantly reduced $[7,8]$. However, there still remains considerate debate whether pneumonectomy itself is a risk factor for postoperative complications or long-term outcome [9-12]. Furthermore, it is still unclear whether induction therapy improves the prognosis of patients underwent pneumonectomy and the efficacy of pneumonectomy for resectable small cell lung cancer (SCLC). Therefore, it is important for surgeons to have a comprehensive understanding of pneumonectomy and avoid surgical risks. Based on this, we analyzed the clinical records of 406 consecutive patients underwent pneumonectomy to identify postoperative complications and the risk factors influencing long-term survival.
Table 2: Postoperative outcomes for patients underwent pneumonectomy.

\begin{tabular}{|c|c|c|}
\hline Event & $\mathrm{N}$ & $\%$ \\
\hline Postoperative stay, $\mathrm{d}$ & $13.6(0-74)$ & \\
\hline ICU stay, $\mathrm{d}$ & $3.4(0-34)$ & \\
\hline \multicolumn{3}{|l|}{ Mortality } \\
\hline 30-day mortality & 13 & 3.2 \\
\hline \multicolumn{3}{|l|}{ Cause of 30-day mortality } \\
\hline Heart arrest & 1 & 7.7 \\
\hline ARDS & 7 & 53.8 \\
\hline $\mathrm{BPF}$ & 3 & 23.1 \\
\hline Thoracic hemorrhage & 1 & 7.7 \\
\hline Cause unknown & 1 & 7.7 \\
\hline 90-day mortality & 25 & 6.2 \\
\hline \multicolumn{3}{|l|}{ Complications } \\
\hline ARDS & 8 & 2.0 \\
\hline Pulmonary infection & 24 & 5.9 \\
\hline Arrhythmia & 103 & 25.4 \\
\hline Wound infection & 3 & 0.7 \\
\hline Transfusion & 90 & 22.2 \\
\hline Gastrointestinal dysfunction & 4 & 1.0 \\
\hline Renal failure & 1 & 0.2 \\
\hline Electrolyte disturbance & 7 & 1.7 \\
\hline Fever & 14 & 3.4 \\
\hline Pulmonary atelectasis & 2 & 0.5 \\
\hline Heart arrest & 4 & 1.0 \\
\hline Empyema & 6 & 1.5 \\
\hline Re-operation (active bleeding) & 7 & 1.7 \\
\hline Cerebral infarction & 1 & 0.2 \\
\hline Chylothorax & 2 & 0.5 \\
\hline Hoarseness & 3 & 0.7 \\
\hline BPF & 10 & 2.5 \\
\hline Internal jugular vein thrombosis & 1 & 0.2 \\
\hline Pleural effusion & 10 & 2.5 \\
\hline \multicolumn{3}{|l|}{ Progression } \\
\hline Recurrence & 189 & 46.6 \\
\hline Local & 51 & 12.5 \\
\hline Distant & 138 & 34.0 \\
\hline No recurrence & 217 & 53.4 \\
\hline
\end{tabular}

\section{Results}

A total of 406 patients underwent pneumonectomy, including 357 men $(87.9 \%)$ and 49 women $(12.1 \%)$, with an average age of 58.4 years (33-76 years). Smokers (84\%) made up the majority. Furthermore, most of the patients underwent left pneumonectomy while squamous carcinoma acted as the most frequent pathological type. (Table 1)

Two patients died intraoperatively due to massive haemorrhage. The 30-day and 90-day mortality rates were $3.2 \%$ and $6.2 \%$, respectively. As for the 30-day deaths, seven patients were caused by acute respiratory distress syndrome (ARDS), three caused by bronchopleural fistula (BPF), one caused by heart arrest and one caused by thoracic hemorrhage, respectively. Postoperative complications developed in 149 patients $(36.7 \%)$, mainly included arrhythmia $(25.4 \%, \mathrm{n}=103)$, transfusion $(22.2 \%, \mathrm{n}=90)$, pulmonary infection $(5.9 \%, \mathrm{n}=24)$, fever $(3.4 \%, 14 \%)$, BPF $(2.5 \%$, $\mathrm{n}=10)$ and ARDS $(2.0 \%, \mathrm{n}=8)$ (Table 2). The average 
ICU stay was 3.4 days (0-34 days) while postoperative hospitalization time was 13.6 days (0-74 days) (Table 2).

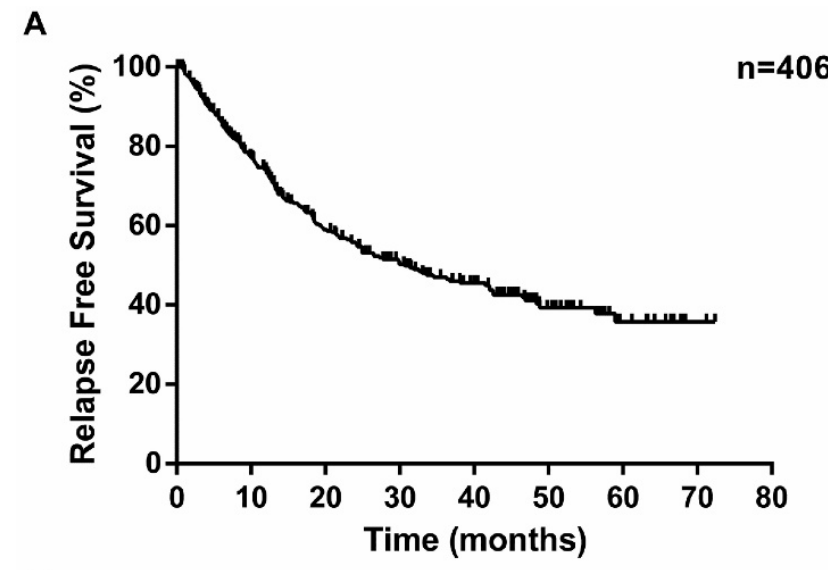

B

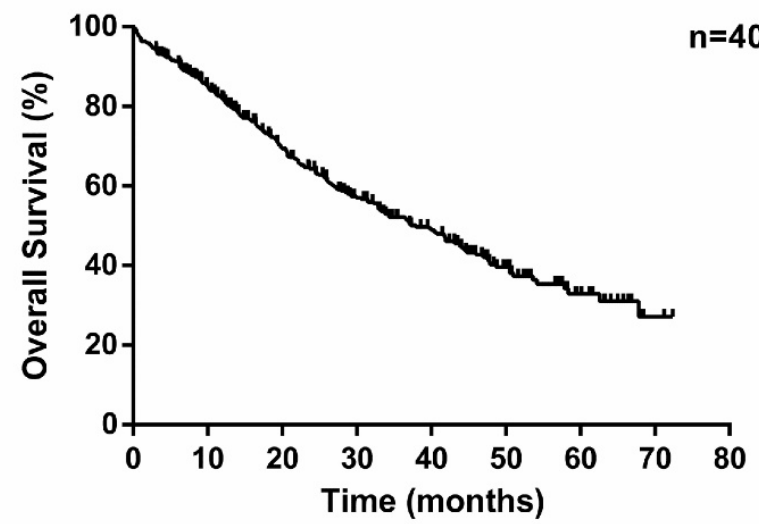

Figure 1: Kaplan-Meier survival curves for relapse-free survival (A) and overall survival (B) according to patients underwent pneumonectomy in our series.

The median survival time was 24.4 months. During the follow-up, 189 patients experienced a relapse, consisting of 51 patients with local recurrence and 138 with distant recurrence (Table 2). The overall 1-year, 3-year and 5-year survival rates were $82.7 \%$, $50.9 \%$ and $32.5 \%$, respectively (Figure 1). Unsurprisingly, with the progression of disease stage or nodal staging, both relapse-free survival (RFS) and overall survival (OS) would be worse (Log-rank $P<0.0001$ ). There was no difference in RFS (Log-rank $P=0.0995$ ) between small cell lung cancer (SCLC) and non-small cell lung cancer (NSCLC), but NSCLC revealed better overall survival (Log-rank $P=0.0181$ ). The overall 1-year, 3-year, 5-year survival rates for patients with NSCLC were $84.1 \%, 52.1 \%$ and $32.5 \%$, respectively, and patients with SCLC were $56.1 \%, 38.5 \%$ and $28.8 \%$, respectively. Among NSCLCs, adenocarcinomas had a worse prognosis than squamous carcinomas. As to laterality, compared to right pneumonectomy, patients with left pneumonectomy had a better prognosis
(OS: Log-rank $P=0.0082$, RFS: Log-rank $P=0.3274$ ). Neoadjuvant chemotherapy did not make sense for improving outcomes of patients underwent pneumonectomy.

Univariable analysis revealed that only nodal stage was a significant predictor of RFS while sex, ICU stay, disease stage, nodal stage and adjuvant chemotherapy were all significant predictors of OS (Table 3). Moreover, ICU stay, disease stage, nodal stage and adjuvant chemotherapy were still significant predictors of OS in multivariable analysis, while sex was not (Table 4).

Table 3: Univariable Analyses for RFS and OS in patients underwent pneumonectomy.

\begin{tabular}{|c|c|c|c|c|c|c|}
\hline & RFS & & & OS & & \\
\hline Variable & HR & $95 \% \mathrm{CI}$ & $p$ & HR & $95 \% \mathrm{CI}$ & $p$ \\
\hline Age, yrs & 0.989 & $\begin{array}{l}0.969 \text { to } \\
1.008\end{array}$ & 0.261 & 1.011 & $\begin{array}{l}0.992 \text { to } \\
1.031\end{array}$ & 0.269 \\
\hline Sex & 0.484 & $\begin{array}{l}0.231 \text { to } \\
1.013\end{array}$ & 0.054 & 0.440 & $\begin{array}{l}0.194 \text { to } \\
0.999\end{array}$ & 0.496 \\
\hline Smoking history & 0.672 & $\begin{array}{l}0.351 \text { to } \\
1.287\end{array}$ & 0.231 & 0.633 & $\begin{array}{l}0.314 \text { to } \\
1.276\end{array}$ & 0.201 \\
\hline ICU stay & 1.017 & $\begin{array}{l}0.953 \text { to } \\
1.085\end{array}$ & 0.607 & 1.056 & $\begin{array}{l}1.009 \text { to } \\
1.106\end{array}$ & 0.019 \\
\hline $\begin{array}{l}\text { Postoperative hospital } \\
\text { stay }\end{array}$ & 0.993 & $\begin{array}{l}0.969 \text { to } \\
1.018\end{array}$ & 0.579 & 0.996 & $\begin{array}{l}0.974 \text { to } \\
1.018\end{array}$ & 0.693 \\
\hline Complication & 1.102 & $\begin{array}{l}0.794 \text { to } \\
1.529\end{array}$ & 0.562 & 1.194 & $\begin{array}{l}0.874 \text { to } \\
1.630\end{array}$ & 0.266 \\
\hline Side & 1.110 & $\begin{array}{l}0.805 \text { to } \\
1.530\end{array}$ & 0.525 & 1.322 & $\begin{array}{l}0.966 \text { to } \\
1.811\end{array}$ & 0.081 \\
\hline Stage & 1.512 & $\begin{array}{l}0.948 \text { to } \\
2.412\end{array}$ & 0.082 & 1.658 & $\begin{array}{l}1.047 \text { to } \\
2.626\end{array}$ & 0.031 \\
\hline T-size, cm & 1.047 & $\begin{array}{l}0.972 \text { to } \\
1.128\end{array}$ & 0.229 & 1.041 & $\begin{array}{l}0.973 \text { to } \\
1.114\end{array}$ & 0.241 \\
\hline N Stage & 1.675 & $\begin{array}{l}1.159 \text { to } \\
2.419\end{array}$ & 0.006 & 1.846 & $\begin{array}{l}1.293 \text { to } \\
2.635\end{array}$ & 0.001 \\
\hline M & 1.089 & $\begin{array}{l}0.373 \text { to } \\
3.178\end{array}$ & 0.876 & 1.328 & $\begin{array}{l}0.482 \text { to } \\
3.662\end{array}$ & 0.583 \\
\hline Pleural invasion & 1.163 & $\begin{array}{l}0.821 \text { to } \\
1.648\end{array}$ & 0.395 & 1.151 & $\begin{array}{l}0.825 \text { to } \\
1.607\end{array}$ & 0.407 \\
\hline Adjuvant chemotherapy & 1.139 & $\begin{array}{l}0.781 \text { to } \\
1.659\end{array}$ & 0.499 & 0.578 & $\begin{array}{l}0.420 \text { to } \\
0.794\end{array}$ & 0.001 \\
\hline $\begin{array}{l}\text { Neoadjuvant } \\
\text { chemotherapy }\end{array}$ & 1.059 & $\begin{array}{l}0.636 \text { to } \\
1.764\end{array}$ & 0.824 & 0.882 & $\begin{array}{l}0.539 \text { to } \\
1.441\end{array}$ & 0.616 \\
\hline Pathology & 0.919 & $\begin{array}{l}0.779 \text { to } \\
1.085\end{array}$ & 0.321 & 1.067 & $\begin{array}{l}0.912 \text { to } \\
1.250\end{array}$ & 0.418 \\
\hline
\end{tabular}

Abbreviations: RFS, relapse-free survival; OS, overall survival; $\mathrm{HR}$, hazard ratio.

Table 4: Multivariable Analyses of OS in patients underwent pneumonectomy.

\begin{tabular}{llll}
\hline & OS & & \\
\hline Variable & HR & $\mathbf{9 5 \%}$ CI & $p$ \\
\hline Sex & 0.632 & 0.392 to 1.020 & 0.060 \\
ICU stay & 1.067 & 1.027 to 1.109 & $\mathbf{0 . 0 0 1}$ \\
Nodal stage & 1.771 & 1.284 to 2.443 & $<\mathbf{0 . 0 0 1}$ \\
Stage & 1.917 & 1.307 to 2.811 & $\mathbf{0 . 0 0 1}$ \\
Adjuvant & 0.534 & 0.394 to 0.724 & $<\mathbf{0 . 0 0 1}$ \\
chemotherapy & & &
\end{tabular}

Abbreviations: OS, overall survival; $H R$, hazard ratio. 
A

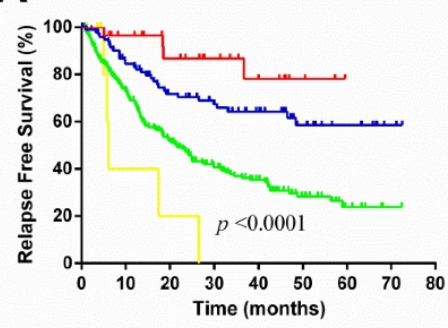

C

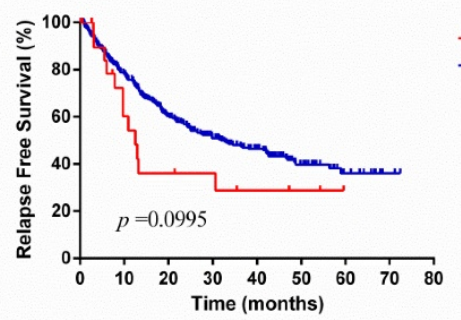

E

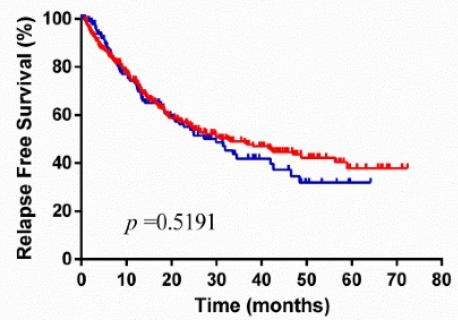

G

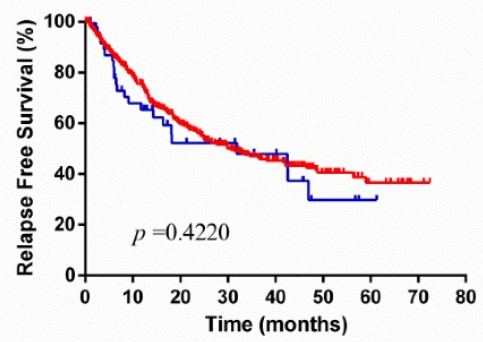

B

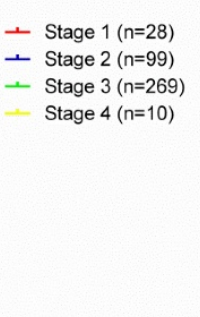

$+\operatorname{SCLC}(n=22)$

- $\operatorname{NSCLC}(n=384)$

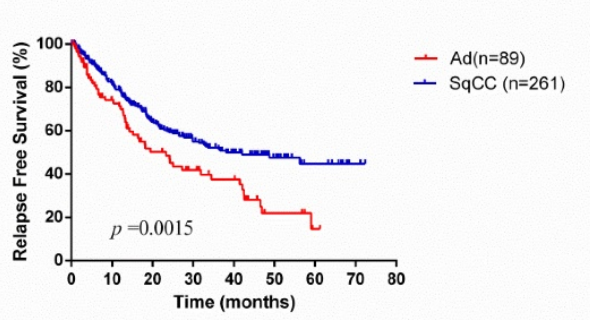

$\mathbf{F}$

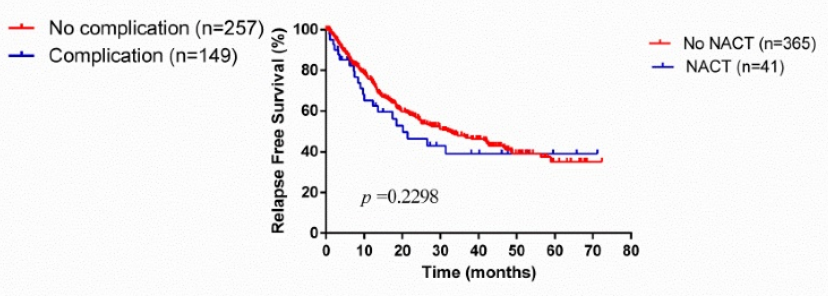

H
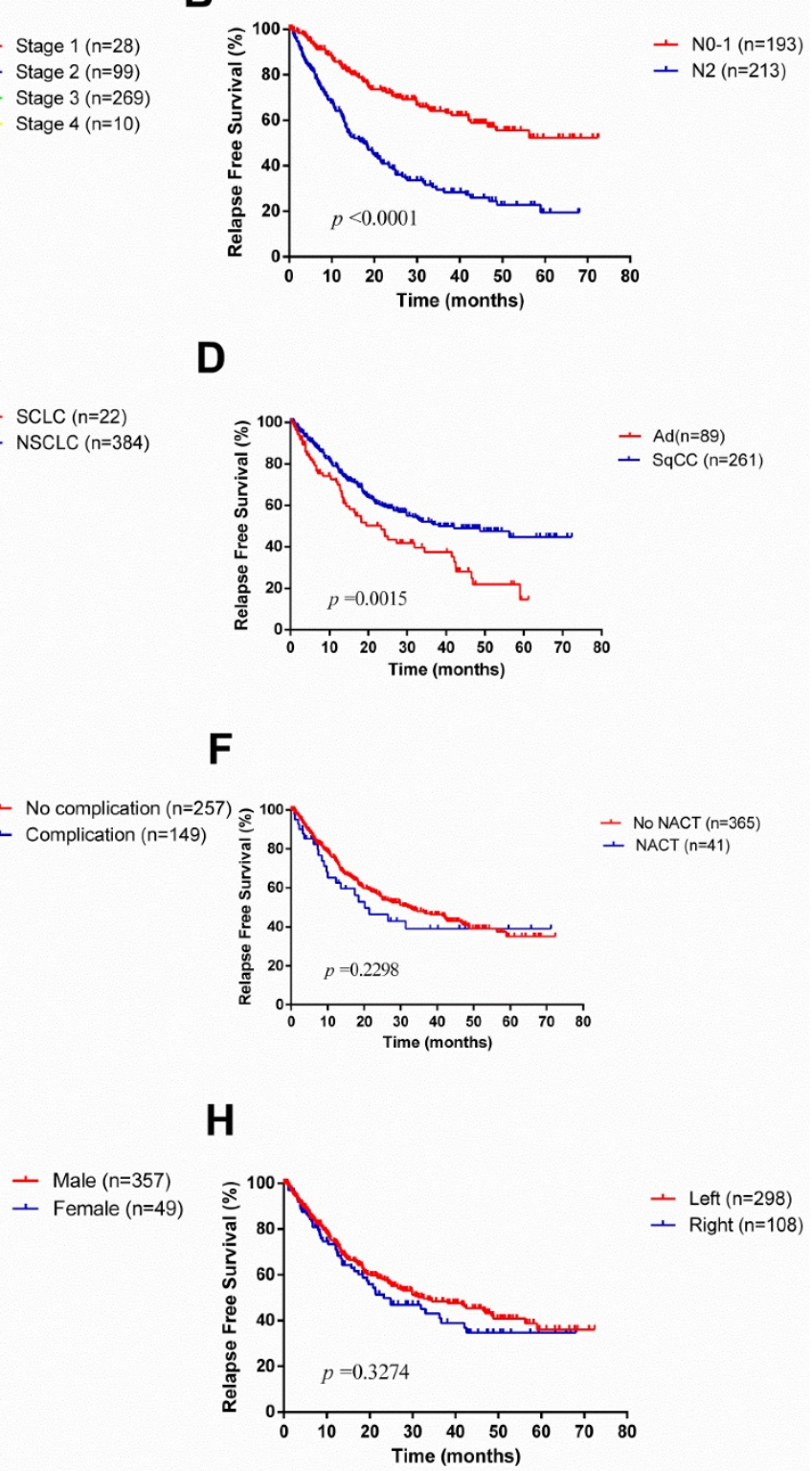

D

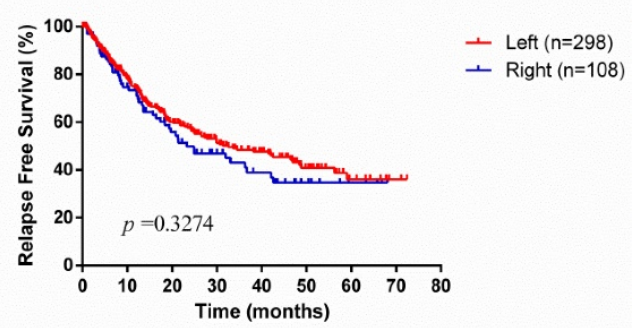

Figure 2: Kaplan-Meier survival curves for relapse-free survival according to different classification criteria in our series.

\section{Discussion}

In recent years, pneumonectomy has been increasingly considered as a high-risk procedure, especially when lesser resections such as sleeve resection have shown no compromise of oncologic results and improved postoperative life quality. However, pneumonectomy is inevitable in terms of extension of lung cancer or technical and anatomical considerations $[13,14]$. Actually, pneumonectomy is associated with relatively higher postoperative morbidity and mortality rates and worse 5-year overall survival when compared with limited resections or even with mere received chemoradiotherapy [4].

Our results revealed reasonable overall morbid- ity and mortality rates, as well as long-term survival for pneumonectomy. Postoperative complications developed in 149 patients (36.7\%) and the 30-day and 90-day mortality rates were $3.2 \%$ and $6.2 \%$, respectively. The early-death rate is basically in line with previous studies reported by several authors [13, 15-17]. Furthermore, the overall 1-year, 3-year and 5 -year survival rates were $82.7 \%, 50.9 \%$ and $32.5 \%$, respectively. Our results were comparable to that of prior studies [13, 15-17]. In multivariable analysis, we detected ICU stay, disease stage, nodal stage and adjuvant chemotherapy as significant predictors of OS, whereas older age, BPF, adenocarcinoma cell type, right pneumonectomy, male sex and tumor size were also significant predictors of OS in other reports $[15,18]$. 
A

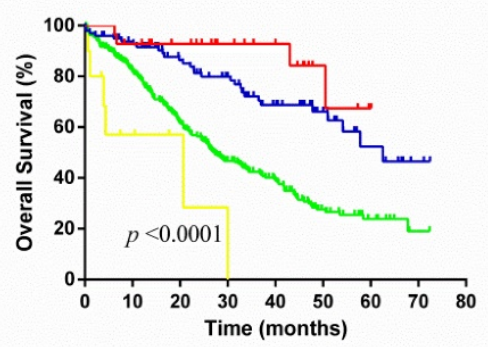

C

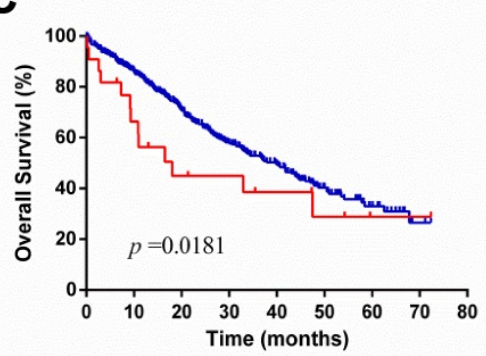

E

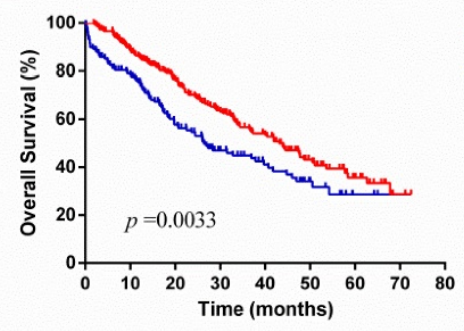

G

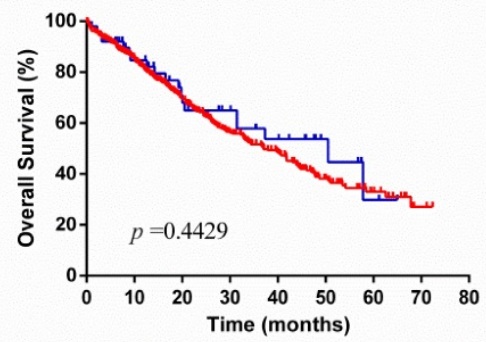

B
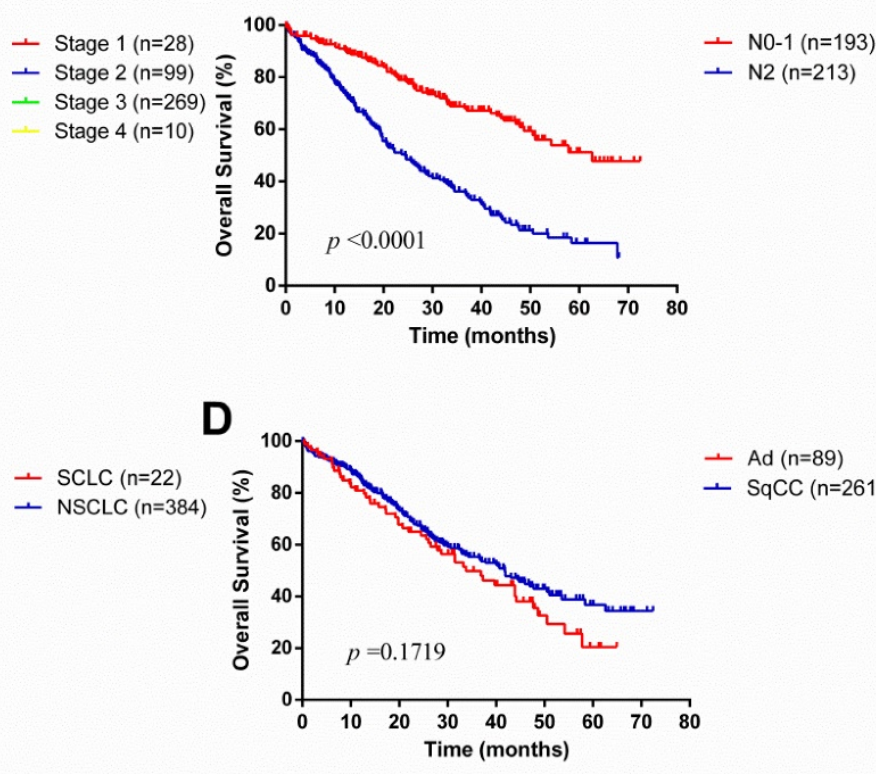

D

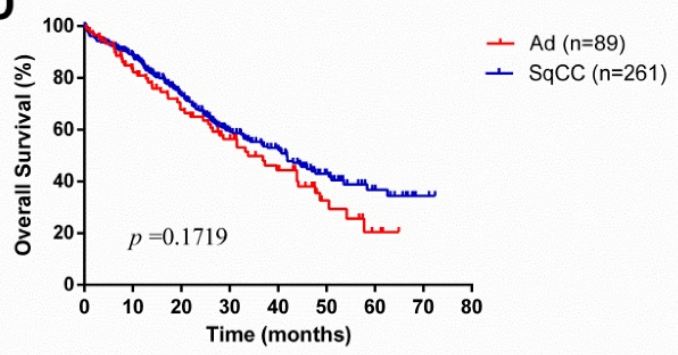

$\mathbf{F}$

- No complication $(n=25$
- Complication $(n=149)$

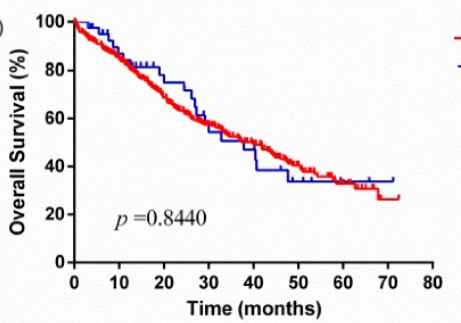

- No NACT $(n=365)$ - NACT $(n=41)$

H

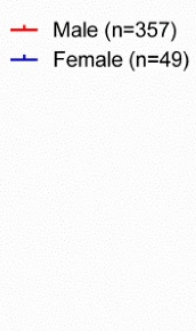

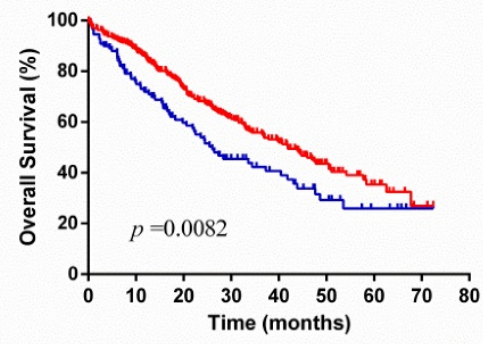

Figure 3: Kaplan-Meier survival curves for overall survival according to different classification criteria in our series.

With regards to laterality, compared to right pneumonectomy, patients with left pneumonectomy had a better prognosis in OS, but no significant difference in RFS. Furthermore, perioperative morbidity and mortality occurred more frequently in right pneumonectomy. Some studies have similar results. Qadri et al. [19] reported median survival was better in left pneumonectomy (left 2.7 years vs. right 1.9 years), as well as an improved long-term survival (Log-rank $\mathrm{P}=0.006$ ). Fernandez and associates [18] reviewed 9746 patients underwent pneumonectomy in the Surveillance, Epidemiology, and End Results (SEER) database, and found a right pneumonectomy is correlated with almost twice the perioperative mortality as a left pneumonectomy. Postoperative ARDS and BPF used to appear mostly in a right pneumonectomy $[15,20,21]$. The reason for increased frequency of postoperative ARDS after a right pneumonectomy is that the left lung would be more likely to overload as the larger right lung has greater compensatory function. Most patients have 1 right bronchial artery whereas 2 or more bronchial arteries in the left, which associated with increased incidence of BPF in patients with right pneumonectomies.

The role of neoadjuvant therapy is still uncertain. In our study, whether neoadjuvant therapy was received or not, this factor would not affect postoperative morbidity or long-term survival. Similarly, 
Mansour et al. [22] found pneumonectomy is a feasible procedure, which would not increase the postoperative morbidity rate even after neoadjuvant therapy. As Margaritora et al. [23] reported, even in right pneumonectomy, patients received neoadjuvant therapy had lower mortality rate. On the contrary, some studies revealed patients underwent pneumonectomy would have high morbidity and mortality rates after neoadjuvant therapy [24-26]. Based on these separated views above, we suggest a thorough evaluation for patients should be taken before pneumonectomy whether an induction therapy is needed.

SCLC is considered as a systemic disease in terms of its rapid progress. The standard treatment for patients with SCLC is chemoradiotherapy, even for those diagnosed with limited-stage disease [27]. The role of surgical resection is still controversial in patients with SCLC. In our series, a total of 22 patients with SCLC were treated with pneumonectomy, which pathological stage was almost all stage III disease (19 of 22). There was no difference in RFS (Log-rank $P$ $=0.0995$ ) between SCLC and NSCLC, but NSCLC revealed better overall survival (Log-rank $P=0.0181$ ). The overall 1-year, 3-year, 5-year survival rates for patients with SCLC were $56.1 \%, 38.5 \%$ and $28.8 \%$, respectively. The 5-year survival rate was similar to what Kawano et al. reported (28.6\%) [28], but much lower than what Stish et al. did (37\%) [29], due to their patients having relatively early-stage disease (stage I SCLC accounts for 56\%). Interestingly, the difference still existed whether pneumonectomy was a good option for patients with SCLC. Kawano and colleagues found pneumonectomy (HR 6.177, $P$ $=0.00159$ ) acted as a significant independent predictor of an adverse outcome while others reported patients underwent lobectomy/pneumonectomy (HR 1.0, P $=0.01$ ) were less likely to experience intrathoracic recurrences [28, 29]. From the current study, we achieved acceptable survival outcomes in well-selected SCLC patients through pneumonectomy, but we could not further analyze the surgical outcomes of different procedures. Multidisciplinary treatment is still needed for patients with SCLC.

There are some limitations of this study. First, thirty patients $(6.9 \%)$ were lost to follow-up, which would relatively reduce the morbidity and mortality rates. Second, many patients had their induction therapies in their local hospitals and the specific treatments were unknown. Third, as for patients with SCLC, although the acceptable survival outcomes were achieved, whether pneumonectomy acts as a risk factor or an innocent bystander is still unknown. Further study should be taken in the future.
In summary, our finding demonstrated that pneumonectomy is still a valuable and effective treatment option for patients with advanced lung cancer. Surgeons should be more cautious when patients have higher disease stage, adenocarcinoma cell type and right-side lung cancer. Neoadjuvant chemotherapy did not affect the prognosis. Pneumonectomy could also achieve acceptable survival outcomes in well-selected patients with SCLC.

\section{Materials and Methods}

\section{Patients}

The study was approved by the Institutional Review Board of our hospital and the signed informed consent for surgery was provided. During the period between January 2010 and December 2012, the clinical records of patients who underwent pneumonectomy in our hospital were retrospectively reviewed. All the patients had preoperative assessment to exclude distant metastases, including chest CT scans, abdominal CT or ultrasound examination, brain CT scan and technetium bone scan. Endobronchial ultrasound-guided transbronchial needle aspiration (EBUS-TBNA) or positron emission tomography (PET)-CT scan was also an option for excluding distant metastases. Patients with biopsy-verified distant metastases were also excluded. Chemoradiotherapy was recommended first for patients diagnosed as advanced NSCLC (IIIB or more) or SCLC by preoperative biopsy (needle aspiration or bronchoscopy).

Patients underwent pneumonectomy for completion pneumonectomy, benign diseases or pulmonary metastases of other tumors were all excluded. After the exclusion, a total of 436 patients met the standard. Among these patients, thirty patients were lost to follow-up and finally 406 patients were subjected to the study. Patients with SCLC were treated with pneumonectomy in our study because of the negative preoperative biopsy results. The archives for all patients were reviewed and relevant clinicopathologic data including age, gender, smoking history, surgical treatment, postoperative complications and tumor staging (according to the 7th AJCC TNM staging system [30]) were reviewed as well. All the patients were followed up through out-patient clinic or telephone every 3 months for the first year after surgery, every 6 months for the next 3 years and then annually.

\section{Statistical analysis}

All the clinicopathologic data and distributions of survival were analyzed by SPSS 19.0 software package (SPSS Inc., Chicago, IL) or Prism 5 (Graphpad Software Inc., La Jolla, CA). The curves of relapse-free 
survival (RFS) and overall survival (OS), as well as their comparisons, were calculated by Kaplan-Meier method and the log-rank test. $P<0.05$ was considered statistically significant.

\section{Abbreviations}

SCLC: small cell lung cancer

NSCLC: non-small cell lung cancer

RFS: relapse-free survival

OS: overall survival

ICU: intensive care unit

ARDS: acute respiratory distress syndrome

BPF: bronchopleural fistula

SEER: Surveillance, Epidemiology, and End Results

CT: computed tomography

EBUS-TBNA: endobronchial ultrasound-guided

transbronchial needle aspiration

PET: positron emission tomography

NACT: neoadjuvant chemotherapy

\section{Acknowledgments}

This work was supported by giants from National Natural Science Foundation of China (81572253, 81330056, 81401886, 81401891， 81422029 and 81372525), Shen-kang Center Project (SKMB1201), shanghai municipal commission of health and family planning [No. 2013ZYJB0004, No. 201540139] and Shanghai Committee of Science and Technology, China [No. 16QA1403500].

\section{Author Contributions}

\section{Jianxin Shi}

Conception and design: Haiquan Chen and

Administrative support: Haiquan Chen and Jianxin Shi

Provision of study materials or patients: Chang

$\mathrm{Gu}$, Rui Wang and Xufeng Pan

Collection and assembly of data: Chang $\mathrm{Gu}$, Qingyuan Huang, Jizhuang Luo and Yiyang Wang

Data analysis and interpretation: Chang Gu, Rui

Wang, Xufeng Pan and Jiajie Zheng

Manuscript writing: All authors

Final approval of manuscript: All authors

\section{Competing Interests}

The authors declare that there is no conflict of interest that could be perceived as prejudicing the impartiality of the research reported.

\section{References}

1. Torre L A, Bray F, Siegel RL, et al. Global cancer statistics, 2012. CA Cancer J Clin, 2015, 65(2): 87-108.

2. Gu C, Pan X, Wang R, et al. Analysis of mutational and clinicopathologic characteristics of lung adenocarcinoma with clear cell component. Oncotarget, 2016, 7(17): 24596-603

3. Gómez-Caro A, Garcia S, Reguart N, et al. Determining the appropriate sleeve lobectomy versus pneumonectomy ratio in central non-small cell lung cancer patients: an audit of an aggressive policy of pneumonectomy avoidance. Eur J Cardiothorac Surg, 2011, 39(3): 352-359.

4. Janet-Vendroux A, Loi M, Bobbio A, et al. Which is the Role of Pneumonectomy in the Era of Parenchymal-Sparing Procedures? Early/Long-Term Survival and Functional Results of a Single-Center Experience. Lung, 2015, 193(6): 965-973.

5. Powell ES, Pearce AC, Cook D, et al. UK pneumonectomy outcome study (UKPOS): a prospective observational study of pneumonectomy outcome. J Cardiothorac Surg, 2009, 4(1): 1.

6. Licker M, Spiliopoulos A, Frey JG, et al. Risk factors for early mortality and major complications following pneumonectomy for non-small cell carcinoma of the lung. Chest, 2002, 121(6): 1890-1897.

7. Duque JL, Ramos G, Castrodeza J, et al. Early complications in surgical treatment of lung cancer: a prospective, multicenter study. Ann Thorac Surg, 1997, 63(4): 944-950.

8. Ichiki Y, Nagashima A, Chikaishi Y, et al. Pneumonectomy for non-small cell lung cancer. Surg today, 2012, 42(9): 830-834.

9. Toker A, Dilege S, Ziyade S, et al. Causes of death within 1 year of resection for lung cancer. Early mortality after resection. Eur J Cardiothorac Surg, 2004, 25(4): 515-519.

10. Bernard A, Ferrand L, Hagry $\mathrm{O}$, et al. Identification of prognostic factors determining risk groups for lung resection. Ann Thorac Surg, 2000, 70(4): 1161-1167.

11. Leo F, Solli PG, Veronesi G, et al. Does chemotherapy increase the risk of respiratory complications after pneumonectomy? J Thorac Cardiovasc Surg, 2006, 132(3): 519-523

12. Warwick R, Mediratta N, Shackcloth M, et al. Pneumonectomy: risk factor or innocent bystander? Asian Cardiovasc Thorac Ann, 2014, 22(1):49-54.

13. Pricopi $C$, Mordant $P$, Rivera $C$, et al. Postoperative morbidity and mortality after pneumonectomy: a 30-year experience of 2064 consecutive patients. Interact Cardiovasc Thorac Surg, 2015, 20(3): 316-21.

14. Riquet $M$, Mordant $P$, Pricopi $C$, et al. A review of 250 ten-year survivors after pneumonectomy for non-small-cell lung cancer. Eur J Cardiothorac Surg, 2014, 45(5): 876-881.

15. Alexiou C, Beggs D, Rogers ML, et al. Pneumonectomy for non-small cell lung cancer: predictors of operative mortality and survival. Eur J Cardiothorac Surg, 2001, 20(3): 476-480.

16. Thomas PA, Berbis J, Baste JM, et al. Pneumonectomy for lung cancer: contemporary national early morbidity and mortality outcomes. J Thorac Cardiovasc Surg, 2015, 149(1): 73-83.

17. Saha SP, Kalathiya RJ, Davenport DL, et al. Survival after pneumonectomy for stage III non-small cell lung cancer. Oman Med J, 2014, 29(1): 24

18. Fernandez FG, Force SD, Pickens A, et al. Impact of laterality on early and late survival after pneumonectomy. Ann Thorac Surg, 2011, 92(1): 244-249.

19. Qadri SSA, Chaudhry MA, Cale A, et al. Short-and long-term outcomes of pneumonectomy in a tertiary center. Asian Cardiovasc Thorac Ann, 2016, 24(3): 250-256.

20. Darling GE, Abdurahman A, Yi QL, et al. Risk of a right pneumonectomy: role of bronchopleural fistula. Ann Thorac Surg, 2005, 79(2): 433-437.

21. Mansour Z, Kochetkova EA, Ducrocq X, et al. Induction chemotherapy does not increase the operative risk of pneumonectomy! Eur J Cardiothorac Surg, 2007, 31(2): 181-185.

22. Mansour Z, Kochetkova EA, Santelmo N, et al. Risk factors for early mortality and morbidity after pneumonectomy: a reappraisal. Ann Thorac Surg, 2009, 88(6): 1737-1743.

23. Margaritora S, Cesario A, Cusumano G, et al. Pneumonectomy with and without induction chemo-radiotherapy for non-small cell lung cancer: short and long-term results from a single centre. Eur Rev Med Pharmacol Sci, 2013, 17(1): 29.

24. Shapiro M, Swanson SJ, Wright CD, et al. Predictors of major morbidity and mortality after pneumonectomy utilizing the Society for Thoracic Surgeons General Thoracic Surgery Database. Ann Thorac Surg, 2010, 90(3): 927-935.

25. Kalathiya RJ, Saha SP. Pneumonectomy for non-small cell lung cancer: outcomes analysis. South Med J, 2012, 105(7): 350-354.

26. Bernard A, Deschamps C, Allen MS, et al. Pneumonectomy for malignant disease: factors affecting early morbidity and mortality. J Thorac Cardiovasc Surg, 2001, 121(6): 1076-1082.

27. Johnson BE, Crawford J, Downey RJ, et al. Small cell lung cancer clinical practice guidelines in oncology. J Natl Compr Canc Netw, 2006, 4(6): 602

28. Kawano D, Okamoto T, Fujishita T, et al. Surgical results of resectable small cell lung cancer. Thorac Cancer, 2015, 6(2): 141-145.

29. Stish BJ, Hallemeier CL, Olivier KR, et al. Long-Term Outcomes and Patterns of Failure After Surgical Resection of Small-Cell Lung Cancer. Clin lung cancer, 2015, 16(5): e67-e73.

30. Edge SB, Byrd DR, Compton CC, et al. Cancer staging manual. American Joint Committee on Cancer (AJCC). 7th ed. New York: Springer, 2010. 